\title{
Midazolam-containing Buccal Liquid
}

National Cancer Institute

\section{Source}

National Cancer Institute. Midazolam-containing Buccal Liquid. NCI Thesaurus. Code C113654.

An oromucosal solution containing the maleate salt form of midazolam, a short-acting benzodiazepine derivative, with anxiolytic, hypnotic, anticonvulsant and sedative activities. Upon administration of the solution into the buccal cavity, midazolam exerts its effect by binding to the benzodiazepine receptor at the gamma-aminobutyric acid (GABA) receptor-chloride ionophore complex in the central nervous system (CNS). This leads to an increase in the permeability of chloride channels, membrane hyperpolarization and enhances the inhibitory effect of GABA in the CNS. Midazolam may also interfere with the reuptake of GABA, thereby causing accumulation of GABA in the synaptic cleft. The oromucosal formulation facilitates administration to patients that are unable to swallow. The ethanol in this formulation improves the buccal absorption of midazolam. 